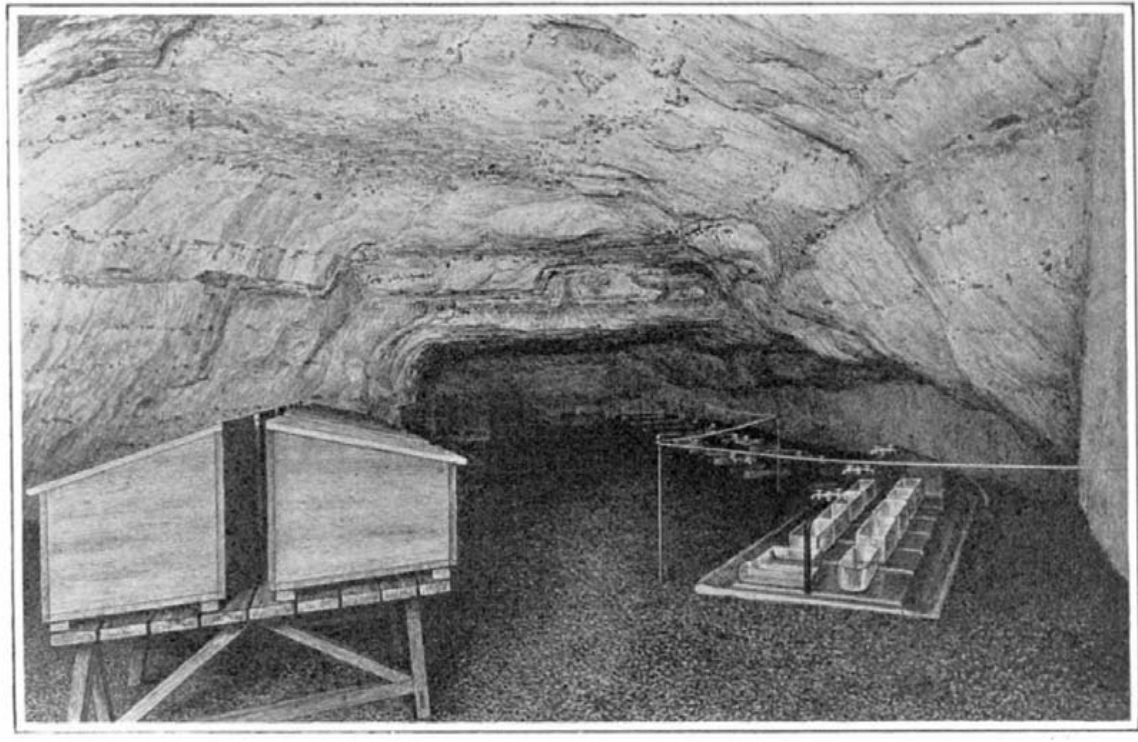

Zoology Hall arranged for breeding small aquatic animals.

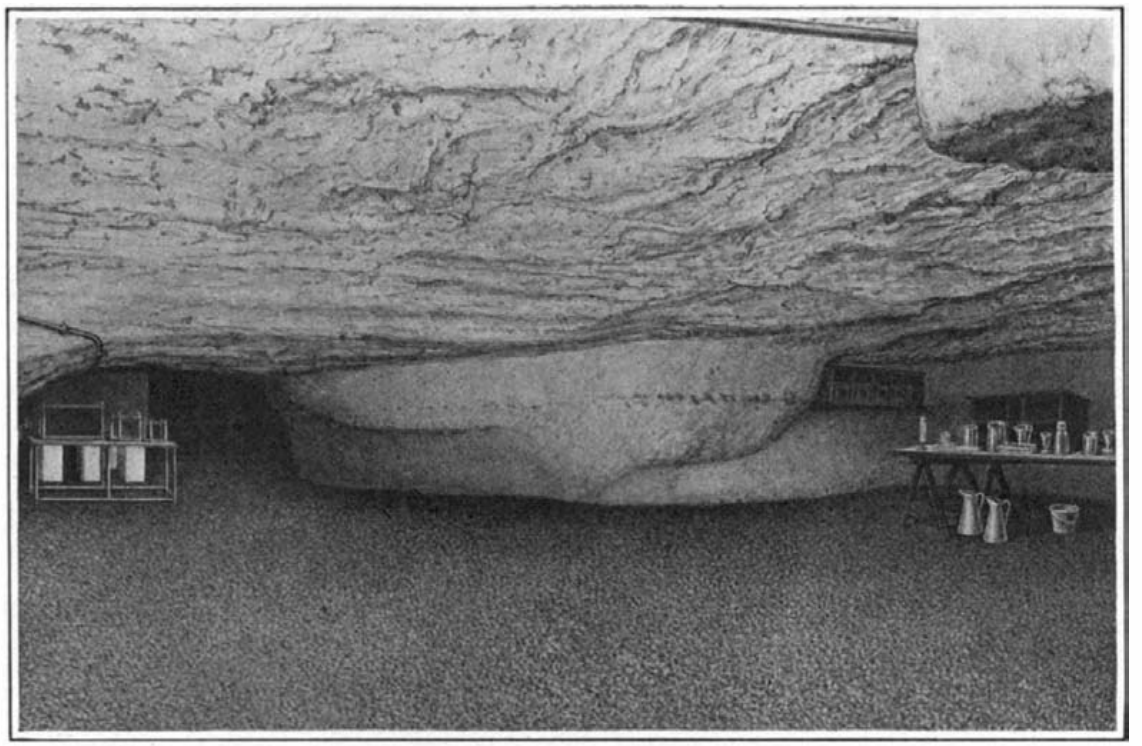

A section of the Vestibule and Zoology Hall.

\title{
A Laboratory for Investigations of Underground Life
}

\author{
A Grotto Utilized for the Study of Subterranean Plants and Animals
}

By Dr. Alfred Gradenwitz

THE organisms inhabiting the bottom of the sea 1 have, until recent times, been omitted from the scope of scientific investigation, and the fauna and flora of caverns, so remarkable on account of their peculiar conditions of existence (absence of light, uniformity of temperature, etc.) have likewise been neglected by scientists until quite recently.

A French naturalist, M. Henri Gadeau de Kerville, in connection with his excavations while searching for remnants of prehistoric man, discovered a large cavern in an abandoned quarry near St. Paer. Being greatly interested in speleology, he decided to prepare this cavern at his own expense as a laboratory for investigating underground life. This remarkable institution, on account of its scientific importance, has stitution, on account of its scientific importance,

The laboratory is situated in calcareous rock and comprises a staircase, a corridor, a ventilation chamber, a vestibule and the laboratory rooms proper. The last include a zoological and a botanical hall and a back room. Apart from the staircase, corridor and ventilation chamber, the whole laboratory covers an area of no less than 671 square meters.

To the left of the entrance there is a concrete water tank of 2,025 liters capacity. From this the water is conveyed through an underground conduit into two sheet-metal tanks in the zoology hall where aquatic animals are kept. From the entrance door there is a concrete staircase of forty steps leading down to the corridor mentioned above. On the left is the ventilablinds, The ventilation of the laboratory is excellent. Even after many hours spent there, one never has the least feeling of being in confined air. Ventilation is effected through the entrance door, the ventilation chamber, a ventilation window in the zoology hall and a large rectangular chimney in the outer wall of the two laboratory halls This wall is lined with a thick layer of earth and stone to protect it against atmospheric influences. A sunshade on the western window of the botany hall protects this against any reflected daylight liable to enter through the ventilation chimney. Since the laboratory lies in the open country the ai in its interior is, of course, of the greatest purity, which is most important in connection with any research work on underground organisms.

In the vestibule there is also a tarred linen curtain which, in bright daylight and especially in the event of the sun rays striking the entrance door, wards off any reflected light. As there is absolute darkness in the two laboratory rooms, there is no need for the wall and ceilings being blackened. In front of the protective curtain is a table for preparing the plants to be used for experimental purposes; behind this table is an insect cage.

The zoology hall contains four aquaria, the two sheetmetal water tanks above referred to, sixteen concrete troughs, a sink, a concrete slab, and on two long table twenty-four wooden boxes. Some of the concrete trough are fitted with lids, thus preventing the animals kep therein from escaping. The water from the four aquaria is discharged through a tap into buckets; a hand pump or syphon serves to renew the water in the iron concrete troughs. Since the air is saturated with moisture there is practically no vaporization of water and on account of its low temperature the water decay with extreme slowness, thus necessitating a renewal at very rare intervals. On the wall there are severa small outlets to the discharge conduit, into which any superfluous water is poured. Candle lanterns with yellow and green glasses are used for lighting. Thes allow sufficient light to pass, though arresting practically all chemical rays.

The botany hall contains four border-beds containing a layer at least 70 centimeters thick of vegetable soil. There are also provided a small stock of vegetable soil, a shelf $\mathbf{1 1 . 6 0}$ meters long and 0.65 meter wide, an iron bracket 2 meters in height and a small table. In th back room are stored some insect cages of wood and wire gauze.

The temperature of the air (generally 5 to $9 \mathrm{deg}$. Cent.) varies only a few degrees in the course of the year, in spite of the excellent ventilation. The water temperature throughout the year is 7 to $8.5 \mathrm{deg}$. Cent M. de Kerville does nothing to prevent an increase of temperature in his cavern laboratory. However, when the outside temperature is excessively low, as an additional precaution he puts a straw mat on the entrance door, which, though interfering in no way with ventilation, constitutes an effectual protection against the cold $\mathrm{On}$ account of the uniform temperatur great moisture of the air and the perfect darkness any plants and animals studied in the laboratory are under practically the same conditions as in real grottoes and the institution promises to prove of the greatest utility to scientific investigation.

\section{Animal Training by Magnetism}

A MONG the various applications of the electro-mag$\mathbf{A}_{\text {net there is one which, while not altogether free }}$

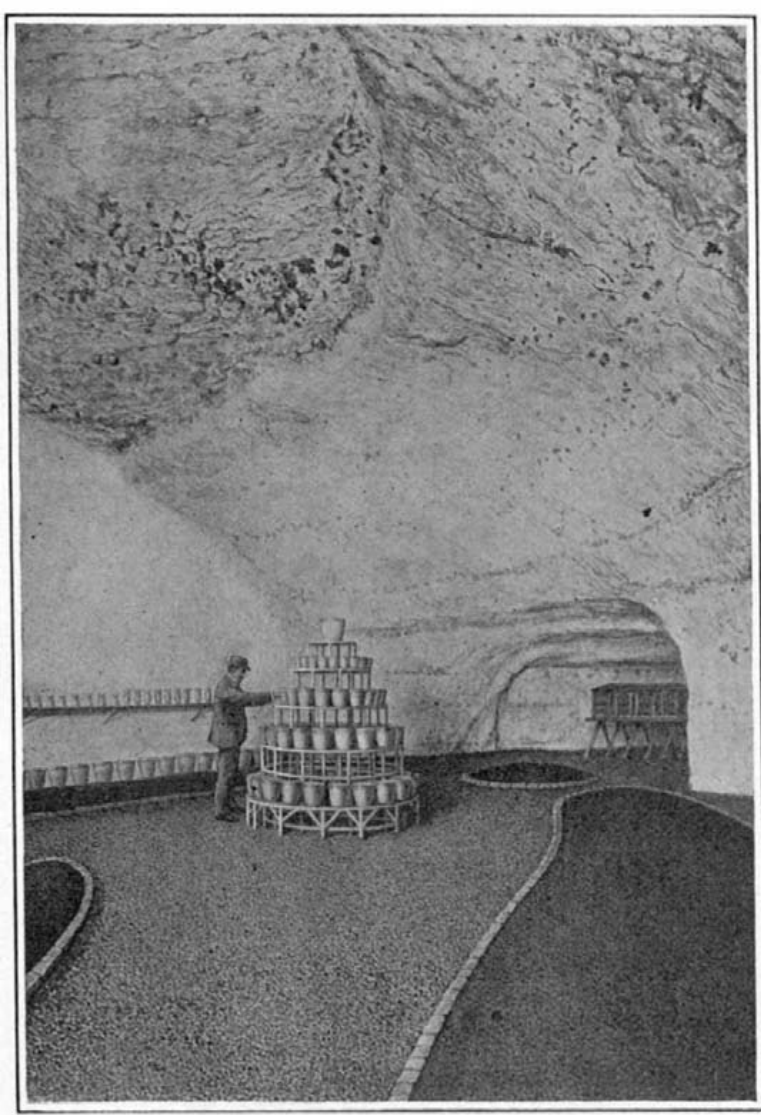

Botany Hall, where underground plants are studied. from the imputation of humbugging the public, has at least the merit of much ingenuity, and may suggest ther and more creditable services.

A genial showman, not so very long ago, happening to see the ease with which a powerful lifting magnet was used to handle material, conceived the idea of employing a similar device to assist the performances of a "trained" elephant. The plan was nothing less than the use of what might be called magnetic stencils, to enable the intelligent beast to appear to solve problems in arithmetic and write answers to simple questions.

It was found entirely possible to train the elephant to take up in his trunk an iron holder containing a piece of chalk, and to move it about over the surface of a blackboard. The problem lay in the conversion of these aimless scribblings into intelligent and correct answers to questions put, either by the trainer or by the audience.

The sight of the lifting magnet gave the showman the clue to his solution. Before long his exhibition included a wagon with a blackboard side, as thin as might be conveniently made, and containing within it a complete equipment of large letters and figures arranged as poles to a powerful magnet, which could be held up against the inside of the blackboard by an attendant The attraction of these magnetized symbols was sufficient to guide the holder in the trunk of the elephant, as it was aimlessly moved over the surface of the blackboard, and thus the intelligent animal was enabled to impress the admiring audience with his ability to write the sums of small numbers and do other things indicative of the possession of human reasoning powers.

In view of the interest now expressed in intelligent horses and similar animal marvels, it may be of interest to examine the extent to which the latest developments in applied science are being used in such fields as the entertainment of a circus audience. Possibly the explanations which this line of inquiry may suggest will be as entertaining as the show itself, and very probably further applications will occur both to showman and scientist.

\section{Excessive Whaling in the Southern Orean}

$W^{T \text { ITH }}$ the recent great development of whaling in Wouthern latitudes has arisen the danger that some of the favorite whaling grounds will soon be worked out. Thanks to modern methods and apparatus, whaling is much more deadly to-day than it was in the palmy whaling days of the last century; not only are to the nu ers, but it is now profitable to hunt species that were formerly not thought worth the attention of whalers. During the yea 1911 about 17,500 whales were caught in the southern hemisphere, yielding 500,000 barrels of oil, valued at $\$ 8,750,000$; and the total catch in 1912 is supposed to have been 10 to 25 per cent greater than in 1911. In South Georgia, where the whaling stations are leased by the British government to a Norwegian firm, 7,000 whales were captured in 1911, the species hunted in that vicinity being chiefly rorquals, which were once left in peace by whalers on account of their relatively small yield of oil and whalebone. The British Colonia Office has just sent Major Barrett-Hamilton to this whaling ground to ascertain whether the whales stand in danger of extermination. $\mathrm{He}$ is accompanied by a taxidermist of the British Museum, who will bring back specimens for the Museum. 